\title{
Clinical characteristics of chronic lymphocytic leukemia in young versus old age patients in Kurdistan region- Iraq
}

\author{
LARA LATEEF ABDULRAHMAN ${ }^{1 *}$, RANAN KARDAGH POLUS ${ }^{2}$, GHANIM SALIM NUMAN ${ }^{3}$ \\ ${ }^{1}$ M.B.Ch.B., A Rainee at Kurdistan Board-Hematology-Nanakali Teaching Hospital, Erbil, Kurdistan Region-Iraq. \\ ${ }^{2}$ M.B.Ch.B, FIBMS, IFCAP; Assistant professor of Hematopathology; College of Medicine-Hawler Medical University, Erbil, Kurdistan \\ Region-Iraq \\ ${ }^{3}$ M.B.Ch.B, FIBMS; Internal Medicine (Clinical Hematologist)-Nanakali Teaching Hospital, Erbil, Kurdistan Region-Iraq. \\ ${ }^{*}$ Corresponding author: Email: lara2018lateef@gmail.com
}

\begin{abstract}
Background: Chronic lymphocytic leukemia is the common adulthood leukemic type, although the incidence rate in the Kurdistan region is low. It is well known that chronic lymphocytic leukemia is prevalent among the elderly age group, however frequent cases of chronic lymphocytic leukemia are newly diagnosed at a younger age.

Aim of the study: To analyze the difference in disease presentation, progression, and outcome between young and old age group patients with chronic lymphocytic leukemia in the Kurdistan region/Iraq.

Patients \& Methods: A retrospective cross-sectional review study carried out in three oncology centers in the Kurdistan region (Nanakaly Hospital in Erbil city, Hiwa center in Sulaimani city, and Azadi center in Duhok city) for ten years through the period from 1st of January, 2010 to 31st of December, 2019 on a convenient sample of 152 patients with chronic lymphocytic leukemia. Diagnosis of chronic lymphocytic leukemia was done by the Oncologists in Kurdistan tumor centers according to the International Workshop on Chronic Lymphocytic Leukemia. The age of patients at diagnosis was categorized into two groups and ranged from 25 years to 94 years. The age cutoff value in the current study was (55 years) depending on previous kinds of literature.

Results: The mean age at diagnosis of patients was ( 63 years); $28 \%$ of them were diagnosed at age of $\leq 50$ years and $72 \%$ of them were diagnosed at age of more than 55 years. Older age patients were significantly presented with weight loss, while younger age patients were significantly presented with neck lumps. There was a highly significant association between the advanced ECOG performance scale and older age patients at diagnosis. A significant association was observed between the death outcome of chronic lymphocytic leukemia and older age patients at diagnosis. The mean survival duration of younger age patients at diagnosis was significantly longer than the mean survival duration of older age patients at diagnosis. Conclusions: clinical presentation, physical status, death rates, and survival of patients with chronic lymphocytic leukemia in Kurdistan region-Iraq are different between young and older age patients.

Keywords: Chronic Lymphocytic Leukemia, age, death, Survival.
\end{abstract}

\section{INTRODUCTION}

Chronic lymphocytic leukemia (CLL) is the most common leukemic type reported among the older age population in the Western world ${ }^{1}$. In Kurdistan, the median age of patients diagnosed with chronic lymphocytic leukemia is (65 years). However, the incidence of CLL in Western countries is higher than in Asian countries including Iraqi Kurdistan ${ }^{2,3}$. The CLL is an indolent malignancy presented with an increase in producing mature B lymphocytes which are dysfunctional. It is known as a monoclonal lymph proliferative disorder recognized with proliferating and accumulating of abnormal morphology mature but immunologically improperly functioning beta cell lymphocytes that are observed in peripheral blood, lymph nodes, spleen, and bone marrow ${ }^{4}$. The pathogenesis of chronic lymphocytic leukemia is not exactly obvious. The genetic factors play a significant role in CLL development and also environmental factors are important in the pathogenesis of CLL but with less effect. Additionally, many risk factors were found to be related to the etiology of chronic lymphocytic leukemia like exposure to chemical agents, irradiation, and tobacco smoking ${ }^{5-7}$.

The pathophysiology of chronic lymphocytic leukemia is characterized by two steps causing replication of beta lymphocytes; first developing monoclonal B-cell lymphocytosis cells caused by risk factors and second progressing from monoclonal B-cell lymphocytosis cells to chronic lymphocytic leukemia caused by genetic and environmental factors. Mutated CD5+ B cells play role in the genesis of monoclonal B-cell lymphocytosis 8 . Abnormal histopathology findings of CLL are firstly recorded in peripheral blood and bone marrow. The classical smudge cells in peripheral blood are pathological markers of CLL. Analyzing peripheral blood by immune phenotype showed lower immunoglobulin level, B-cell associated antigens, and higher levels of CD5 cells. The chromosomal abnormalities in CLL patients like $17 \mathrm{p}$. deletion is detected through fluorescence in situ hybridization 8,9 .

The diagnosis of chronic lymphocytic leukemia is dependable on history, physical examination, complete blood picture, immunephenotyping, fluorescence in situ hybridization, bone marrow aspiration/biopsy, an excisional lymph node histology. Although most CLL cases are asymptomatic, the common CLL symptoms are fever, weight loss, night sweats, and generalized fatigue ${ }^{8}$. Physical examination of CLL patients revealed lymphadenopathy, splenomegaly, and hepatomegaly in most cases. To classify the CLL into three specific prognostic groups or classifying them into high or low-risk groups, two clinical staging systems were introduced and widely accepted ${ }^{10,11}$. The CLL Rai staging system is widely applied in the United States, while the Binet staging is widely popular in Europe. These staging systems 
successfully detect the significance of marrow function and specify the advanced risk or late stages of CLL commonly depending on present anemia or thrombocytopenia ${ }^{1}$. The management of CLL is depending on the clinical status of patients, disease staging, and their fitness. The treatment option in the majority of mild chronic lymphocytic leukemia is to watch and waits. Chemotherapy and chemo immunotherapy treatment had prognostic significance. However, the allogeneic hematopoietic stem cell transplantation is the definite curable choice $8,12,13$.

The age of the patient is considered a common prognostic factor for chronic lymphocytic leukemia. The chronic lymphocytic leukemia represented about one-third of leukemia types leukemia among adults ${ }^{14}$ with an age range of $65-70$ years at diagnosis ${ }^{15}$, however, the CLL is diagnosed among young age population ( $<55$ years) in about $20-30 \%$ of patients ${ }^{16}$. Chronic lymphocytic leukemia is regarded as hematological cancer with a highly heterogeneous trend as some CLL cases expressed aggressiveness and rapidly evolving changes despite long survival ${ }^{17}$. CLL survival is found to be ranged between five to ten years ${ }^{18}$. The survival of younger age CLL patients' survival period is also affected by many disease complications or adverse effects of CLL treatment ${ }^{19}$.

Chronic lymphocytic leukemia is a less frequent type of leukemia in Iraq $^{20}$ and about half the CLL cases in the Kurdistan region are at advanced risk ${ }^{21}$. Recently, better treatment regimens were administered increasingly for Iraqi patients with better outcomes of CLL ${ }^{22}$, regardless of their age at diagnosis. Moreover, national researches studying the effect of CLL patients' age on survival and outcomes of patients are scarce. All of these urged us to conduct this study which aimed to analyze the difference in disease presentation, progression, and the outcome between young and old age group patients with chronic lymphocytic leukemia in the Kurdistan region/Iraq.

\section{PATIENTS AND METHODS}

The present study was a retrospective cross-sectional review study conducted in three oncology centers of Kurdistan region (Nanakaly Hospital in Erbil city, Hiwa center in Sulaimani city, and Azadi center in Duhok city) throughout the ten years from $1^{\text {st }}$ of January, 2010 to $31^{\text {st }}$ of December, 2019. The study population was a review of data for all chronic lymphocytic leukemia patients admitted to three oncology centers in the Kurdistan region. The inclusion criteria included patients with chronic lymphocytic leukemia from all age groups, diagnosed by flow cytometry or bone marrow biopsy with immunohistochemistry, treated and untreated patients. The exclusion criteria were patients with a disease duration of less than one year, other lowgrade lymph proliferative disorders, and missing data. The ethical considerations were implemented according to the Helsinki Declaration regarding ethical approval of Health authorities; ethical approval was taken from the Kurdistan Board Ethical Committee and confidentiality of data. A convenient sample of 250 patients was selected after eligibility to inclusion and exclusion criteria.

The data were collected by the researcher from saved records of CLL patients in three oncology centers and some information was collected directly from patients and fulfilling a prepared questionnaire. The questionnaire was designed by the researchers depending on previous literature. The questionnaire included the followings: general characteristics of CLL patients (age at diagnosis, gender, and location of tumor center) presenting symptoms of patients (incidental diagnosis, fever, sweating, weight loss, fatigue, bleeding, neck lump, and abdominal fullness), physical signs (spleen, liver, peripheral lymph nodes and time from signs to diagnosis), clinical staging classifications (Rai and Binet staging systems), physical status (Eastern Cooperative Oncology Group performance status), treatment types and outcome (current status and survival duration). Diagnosis of CLL was done by the Oncologists in Kurdistan tumor centers according to the International Workshop on Chronic Lymphocytic Leukemia (iwCLL) ${ }^{8}$.

The age of CLL patients at diagnosis was categorized into two groups and ranged from 25 years to 94 years. The age cutoff value in the current study was (55 years) depending on previous literatures using a similar cutoff value of $23-25$. The residence of CLL patients was distributed into three cities of the Kurdistan Region. The Binet and Rai staging of CLL patients was done by the senior in the tumor center according to medical findings and investigations findings 10,11 . The death and alive outcome was assessed by the researcher. The survival duration of CLL patients was reported according to the duration of follow-up.

The data collected were analyzed statistically by Statistical Package of Social Sciences software version 22. The Chi-square and Fischer's exact tests were applied for analyzing the data is suitable. Kaplan-Meier curve was used to assess the survival duration of CLL patients. The level of significance ( $p$-value) was regarded statistically significant if it was 0.05 or less.

\section{RESULTS}

In the present study, two hundred and fifty patients with chronic lymphocytic leukemia (CLL) with a mean age at diagnosis of (63 years) and range of $35-91$ years; $28 \%$ of patients were diagnosed at age of $\leq 50$ years and $72 \%$ of them were diagnosed at age of more than 55 years. Male CLL patients were more than females, with a male to female ratio of 2.1:1. The patients were distributed to oncology centers in Kurdistan; Sulaimani (41.2\%), Hawler (48.8\%), and Duhok (10\%). (Table 1)

Table 1: General characteristics of CLL patients.

\begin{tabular}{|c|c|c|}
\hline Variable & No. & $\%$ \\
\hline \multicolumn{3}{|c|}{ Age at diagnosis mean $\pm S D(63 \pm 11.8$ years $)$} \\
\hline$\leq 55$ years & 70 & 28.0 \\
\hline$>55$ years & 180 & 72.0 \\
\hline \multicolumn{3}{|l|}{ Gender } \\
\hline Male & 170 & 68.0 \\
\hline Female & 80 & 32.0 \\
\hline \multicolumn{3}{|c|}{ Tumor center } \\
\hline Sulaimani & 103 & 41.2 \\
\hline Hawler & 122 & 48.8 \\
\hline Duhok & 25 & 10.0 \\
\hline Total & 250 & 100.0 \\
\hline
\end{tabular}


The incidental diagnosis of CLL was recorded in $34.4 \%$ of patients, while the presenting symptoms of CLL were fever $(29.2 \%)$, sweating $(23.6 \%)$, weight loss $(21.7 \%)$, fatigue $(46.8 \%)$, bleeding (2\%), neck lump (23.6\%) and abdominal fullness (12\%). (Table 2)

Table 2: Presenting symptoms of CLL patients.

\begin{tabular}{|c|c|c|}
\hline Variable & No. & $\%$ \\
\hline \multicolumn{3}{|c|}{ Incidental diagnosis } \\
\hline Yes & 86 & 34.4 \\
\hline No & 164 & 65.6 \\
\hline \multicolumn{3}{|l|}{ Fever } \\
\hline Yes & 73 & 29.2 \\
\hline No & 177 & 70.8 \\
\hline \multicolumn{3}{|l|}{ Sweating } \\
\hline Yes & 59 & 23.6 \\
\hline No & 191 & 76.4 \\
\hline \multicolumn{3}{|c|}{ Weight loss } \\
\hline Yes & 54 & 21.7 \\
\hline No & 195 & 78.3 \\
\hline \multicolumn{3}{|l|}{ Fatique } \\
\hline Yes & 117 & 46.8 \\
\hline No & 133 & 53.2 \\
\hline \multicolumn{3}{|l|}{ Bleeding } \\
\hline Yes & 5 & 2.0 \\
\hline No & 245 & 98.0 \\
\hline \multicolumn{3}{|c|}{ Neck lump } \\
\hline Yes & 59 & 23.6 \\
\hline No & 191 & 76.4 \\
\hline \multicolumn{3}{|c|}{ Abdominal fullness } \\
\hline Yes & 30 & 12.0 \\
\hline No & 220 & 88.0 \\
\hline Total & 250 & 100.0 \\
\hline
\end{tabular}

Table 3: Signs and staging of CLL patients.

\begin{tabular}{|c|c|c|}
\hline Variable & No. & $\%$ \\
\hline \multicolumn{3}{|l|}{ Spleen } \\
\hline No & 123 & 494 \\
\hline Splenomegaly & 126 & 50.6 \\
\hline \multicolumn{3}{|c|}{ Spleen size mean \pm SD $(22.8 \pm 29.1 \mathrm{~mm})$} \\
\hline \multicolumn{3}{|c|}{ Liver } \\
\hline No & 201 & 85.2 \\
\hline Hepatomegaly & 35 & 14.8 \\
\hline \multicolumn{3}{|c|}{ Liver size mean $\pm S D(16.7 \pm 2.1 \mathrm{~mm})$} \\
\hline \multicolumn{3}{|l|}{ Peripheral lymph nodes } \\
\hline No & 122 & 48.8 \\
\hline Lymph node enlargement & 128 & 51.2 \\
\hline \multicolumn{3}{|c|}{ Time from signs to diagnosis mean $\pm S D(2.3 \pm 5.7$ months $)$} \\
\hline \multicolumn{3}{|c|}{ Rai staging } \\
\hline Stage 0 & 62 & 24.8 \\
\hline Stage I & 32 & 12.8 \\
\hline Stage II & 77 & 30.8 \\
\hline Stage III & 24 & 9.6 \\
\hline Stage IV & 55 & 22.0 \\
\hline \multicolumn{3}{|l|}{ Binet stage } \\
\hline Stage A & 118 & 47.2 \\
\hline Stage B & 66 & 26.4 \\
\hline Stage C & 66 & 26.4 \\
\hline Total & 250 & 100.0 \\
\hline
\end{tabular}

Splenomegaly was detected in $50.6 \%$ of CLL patients with a mean spleen size of $(22.8 \mathrm{~cm})$, while hepatomegaly was shown in $14.8 \%$ of patients with a mean liver size of $(16.7 \mathrm{~cm})$. Peripheral lymph node enlargement was found in $51.2 \%$ of CLL patients. Mean time from signs to diagnosis of CLL was (2.3 months). The Rai staging of CLL patients was classified into; stage $0(24.8 \%)$, stage I
(12.8\%), stage II (30.8\%), stage III (9.6\%), and stage IV $(22 \%)$. The Binet stages of CLL patients were staged A $(47.2 \%)$, stage B $(26.4 \%)$, and stage C $(26.4 \%)$. (Table 3$)$

Treatment types of CLL patients were waiting and watch for $34.8 \%$ of them, chemotherapy for $63.6 \%$ of them and $1.6 \%$ of them refused treatment. The ECOG performance scales of studied patients were mainly grade $0(46.4 \%)$ and grade 1 (36\%); followed by grade $2(10 \%)$, grade $3(7.2 \%)$ and grade $4(0.4 \%)$. Death was the outcome of $23.2 \%$ of CLL patients, while $76.8 \%$ of patients are still alive. Mean survival of CLL patients was (35 months); $80.8 \%$ of patients had less than 60 months survival, while $19.2 \%$ of them had survival of 60 months and more. (Table 4)

Table 4: Treatment and outcomes of CLL patients.

\begin{tabular}{|l|l|l|}
\hline Variable & No. & $\%$ \\
\hline Treatment & 87 & 34.8 \\
\hline Watch and wait & 159 & 63.6 \\
\hline Chemotherapy & 4 & 1.6 \\
\hline Refused treatment & \multicolumn{2}{|l|}{} \\
\hline ECOG performance scale & 46.4 \\
\hline Grade 0 & 116 & 36.0 \\
\hline Grade 1 & 90 & 10.0 \\
\hline Grade 2 & 25 & 7.2 \\
\hline Grade 3 & 18 & 0.4 \\
\hline Grade 4 & 1 & \\
\hline Status & 58 & 23.2 \\
\hline Death & 192 & 76.8 \\
\hline Alive & 202 & 80.8 \\
\hline Survival mean $\pm S D(35 \pm 23.8$ months $)$ & 19.2 \\
\hline$<60$ months & 48 & 100.0 \\
\hline$\geq 60$ months & 250 & 6 \\
\hline Total &
\end{tabular}

No significant differences were observed between younger and older age CLL patients at diagnosis regarding gender $(p=0.9)$ and residence $(p=0.8)$. (Table 5)

Table 5: Distribution of CLL patients' general characteristics according to their age at diagnosis.

\begin{tabular}{|c|c|c|c|c|c|}
\hline \multirow{3}{*}{ Variable } & \multicolumn{4}{|c|}{ Age at diagnosis } & \multirow{3}{*}{$\mathbf{P}$} \\
\hline & \multicolumn{2}{|c|}{$\leq 55$ years } & \multicolumn{2}{|c|}{$>55$ years } & \\
\hline & No. & $\%$ & No. & $\%$ & \\
\hline \multicolumn{5}{|l|}{ Gender } & \multirow{3}{*}{$0.9^{N S}$} \\
\hline Male & 48 & 68.6 & 122 & 67.8 & \\
\hline Female & 22 & 31.4 & 58 & 32.2 & \\
\hline \multicolumn{5}{|c|}{ Oncology centers } & \multirow{4}{*}{$0.8^{\mathrm{NS}}$} \\
\hline Sulaimani & 28 & 40.0 & 75 & 41.7 & \\
\hline Hawler & 36 & 51.4 & 86 & 47.8 & \\
\hline Duhok & 6 & 8.6 & 19 & 10.6 & \\
\hline
\end{tabular}

$N S=$ Not significant. 
No significant differences were observed between younger and older age CLL patients at diagnosis regarding incidental diagnosis $(p=0.2)$, fever $(p=0.8)$, sweating $(p=0.6)$, fatigue $(p=0.1)$, bleeding $(p=0.1)$ and abdominal fullness $(p=0.1)$. There was a significant association between weight loss as a presenting symptom of CLL and older age patients at time diagnosis $(p=0.03)$, While a significant association was observed between neck lump presenting symptom of CLL and younger age patients at time of diagnosis $(p=0.002)$. (Table 6)

Table 6: Distribution of CLL presenting according to patients age at diagnosis.

\begin{tabular}{|c|c|c|c|c|c|}
\hline \multirow{3}{*}{ Variable } & \multicolumn{4}{|c|}{ Age at diagnosis } & \multirow{3}{*}{$\mathbf{P}$} \\
\hline & \multicolumn{2}{|c|}{$\leq 55$ years } & \multicolumn{2}{|c|}{$>55$ years } & \\
\hline & No. & $\%$ & No. & $\%$ & \\
\hline \multicolumn{5}{|c|}{ Incidental diagnosis } & \multirow{3}{*}{$0.2^{\mathrm{NS}}$} \\
\hline Yes & 20 & 28.6 & 66 & 36.7 & \\
\hline No & 50 & 71.4 & 114 & 63.3 & \\
\hline \multicolumn{5}{|l|}{ Fever } & \multirow{3}{*}{$0.8^{\mathrm{NS}}$} \\
\hline Yes & 20 & 28.6 & 53 & 29.4 & \\
\hline No & 50 & 71.4 & 127 & 70.6 & \\
\hline \multicolumn{5}{|l|}{ Sweating } & \multirow{3}{*}{$0.6^{\mathrm{NS}}$} \\
\hline Yes & 18 & 25.7 & 41 & 22.8 & \\
\hline No & 52 & 74.3 & 139 & 77.2 & \\
\hline \multicolumn{5}{|c|}{ Weight loss } & \multirow{3}{*}{$0.03^{s}$} \\
\hline Yes & 9 & 12.9 & 45 & 25.1 & \\
\hline No & 61 & 87.1 & 134 & 74.9 & \\
\hline \multicolumn{5}{|l|}{ Fatigue } & \multirow{3}{*}{$0.1^{\mathrm{NS}}$} \\
\hline Yes & 28 & 40.0 & 89 & 49.4 & \\
\hline No & 42 & 60.0 & 91 & 50.6 & \\
\hline \multicolumn{5}{|l|}{ Bleeding } & $0.1^{\mathrm{NS}}$ \\
\hline Yes & 0 & - & 5 & 2.8 & \\
\hline No & 70 & 100.0 & 175 & 97.2 & \\
\hline \multicolumn{5}{|c|}{ Neck lump } & \multirow{3}{*}{$0.002^{s}$} \\
\hline Yes & 26 & 37.1 & 33 & 18.3 & \\
\hline No & 44 & 62.9 & 147 & 81.7 & \\
\hline \multicolumn{5}{|c|}{ Abdominal fullness } & \multirow{3}{*}{$0.1^{\mathrm{NS}}$} \\
\hline Yes & 5 & 7.1 & 25 & 13.9 & \\
\hline No & 65 & 92.9 & 155 & 86.1 & \\
\hline
\end{tabular}

$\mathrm{S}=$ Significant, $N S=$ Not significant

No significant differences were observed between younger and older age CLL patients at diagnosis regarding spleen $(p=0.1)$, spleen size $(p=0.2)$, liver $(p=0.2)$, liver size $(p=0.1)$, peripheral lymph nodes $(p=0.2)$, time from the appearance of symptoms to the time of diagnosis $(p=0.2)$, Rai staging $(p=0.1)$ and Binet stages $(p=0.4)$. (Table 7$)$

No significant differences were observed between younger and older age CLL patients at diagnosis regarding treatment types $(p=0.9)$. There was a highly significant association between advanced ECOG performance scale and older age CLL patients at diagnosis $(p<0.001)$. A significant association was observed between the death outcome of CLL and older age patients at diagnosis $(p=0.01)$. The mean survival duration of younger age CLL patients at diagnosis was significantly longer than the mean survival duration of older age CLL patients at diagnosis $(p=0.04)$. (Table 8)

The overall mean survival of all CLL patients was 41.9 months (median=36 months), the overall mean survival of CLL patients with age of 50 years and less was 43.5 months (median=34 months), while the overall mean survival of CLL patients with age more than 55 years was 40.8 months (median=39 months). (Figure 1)
Table 7: Distribution of CLL signs and staging according to patients' age at diagnosis.

\begin{tabular}{|c|c|c|c|c|c|}
\hline \multirow{3}{*}{ Variable } & \multicolumn{4}{|c|}{ Age at diagnosis } & \multirow{3}{*}{$\mathbf{P}$} \\
\hline & \multicolumn{2}{|c|}{$\leq 55$ years } & \multicolumn{2}{|c|}{$>55$ years } & \\
\hline & No. & $\%$ & No. & $\%$ & \\
\hline \multicolumn{5}{|l|}{ Spleen } & \multirow{3}{*}{$0.1^{\mathrm{NS}}$} \\
\hline No & 29 & 42.0 & 94 & 52.2 & \\
\hline Splenomegaly & 40 & 58.0 & 86 & 47.8 & \\
\hline \multicolumn{5}{|l|}{ Spleen size } & \multirow{2}{*}{$0.2^{\mathrm{NS}}$} \\
\hline Mean $\pm S D(m m)$ & \multicolumn{2}{|l|}{$20.6 \pm 24$} & \multicolumn{2}{|c|}{$23.7 \pm 31.1$} & \\
\hline \multicolumn{5}{|l|}{ Liver } & \multirow{3}{*}{$0.2^{\mathrm{NS}}$} \\
\hline No & 51 & 81.0 & 150 & 86.7 & \\
\hline Hepatomegaly & 12 & 19.0 & 23 & 13.3 & \\
\hline \multicolumn{5}{|l|}{ Liver size } & \multirow[t]{2}{*}{$0.1^{\mathrm{NS}}$} \\
\hline Mean $\pm S D(m m)$ & $17.5 \pm 2.7$ & & 16.2 & & \\
\hline \multicolumn{5}{|c|}{ Peripheral lymph nodes } & \multirow{3}{*}{$0.2^{\mathrm{NS}}$} \\
\hline No & 30 & 42.9 & 92 & 51.1 & \\
\hline Lymph node & 40 & 57.1 & 88 & 48.9 & \\
\hline \multicolumn{5}{|c|}{ Time from signs to diagnosis } & \multirow[t]{2}{*}{$0.2^{\mathrm{NS}}$} \\
\hline Mean $\pm S D$ (month) & $2.9 \pm 4.7$ & & $2 \pm 6$ & & \\
\hline \multicolumn{5}{|l|}{ Rai staging } & \multirow{6}{*}{$0.1^{\mathrm{NS}}$} \\
\hline Stage 0 & 10 & 14.3 & 52 & 28.9 & \\
\hline Stage I & 13 & 18.6 & 19 & 10.6 & \\
\hline Stage II & 23 & 32.9 & 54 & 30.0 & \\
\hline Stage III & 8 & 11.4 & 16 & 8.9 & \\
\hline Stage IV & 16 & 22.9 & 39 & 21.7 & \\
\hline \multicolumn{5}{|l|}{ Binet stages } & \multirow{4}{*}{$0.4^{\mathrm{NS}}$} \\
\hline Stage A & 32 & 45.7 & 86 & 47.8 & \\
\hline Stage B & 16 & 22.9 & 50 & 27.8 & \\
\hline Stage C & 22 & 31.4 & 44 & 24.4 & \\
\hline
\end{tabular}

NS=Not significant.

Table 8: Distribution of CLL patients' treatment and outcome.

\begin{tabular}{|c|c|c|c|c|c|}
\hline \multirow{3}{*}{ Variable } & \multicolumn{4}{|c|}{ Age at diagnosis } & \multirow{3}{*}{$\mathbf{P}$} \\
\hline & \multicolumn{2}{|c|}{$\leq 55$ years } & \multicolumn{2}{|c|}{$>55$ years } & \\
\hline & No. & $\%$ & No. & $\%$ & \\
\hline \multicolumn{5}{|l|}{ Treatment } & \multirow{4}{*}{$0.1^{\mathrm{NS}}$} \\
\hline Watch and wait & 24 & 34.3 & 63 & 35.0 & \\
\hline Chemotherapy & 45 & 64.3 & 114 & 63.3 & \\
\hline Refused treatment & 1 & 1.4 & 3 & 1.7 & \\
\hline \multicolumn{5}{|c|}{ ECOG performance status } & \multirow{6}{*}{$<0.001^{s}$} \\
\hline Grade 0 & 51 & 72.9 & 65 & 36.1 & \\
\hline Grade 1 & 18 & 25.7 & 72 & 40.0 & \\
\hline Grade 2 & 0 & - & 25 & 13.9 & \\
\hline Grade 3 & 1 & 1.4 & 17 & 9.4 & \\
\hline Grade 4 & 0 & - & 1 & 0.6 & \\
\hline \multicolumn{5}{|l|}{ Status } & \multirow{3}{*}{$0.01^{s}$} \\
\hline Death & 9 & 12.9 & 49 & 27.2 & \\
\hline Alive & 61 & 87.1 & 131 & 72.8 & \\
\hline \multicolumn{5}{|l|}{ Survival } & \multirow[t]{2}{*}{$0.04^{s}$} \\
\hline Mean $\pm S D$ & \multicolumn{2}{|c|}{$39.9 \pm 27.9$} & \multicolumn{2}{|c|}{$33.1 \pm 21.8$} & \\
\hline
\end{tabular}

S=Significant, NS=Not significant.

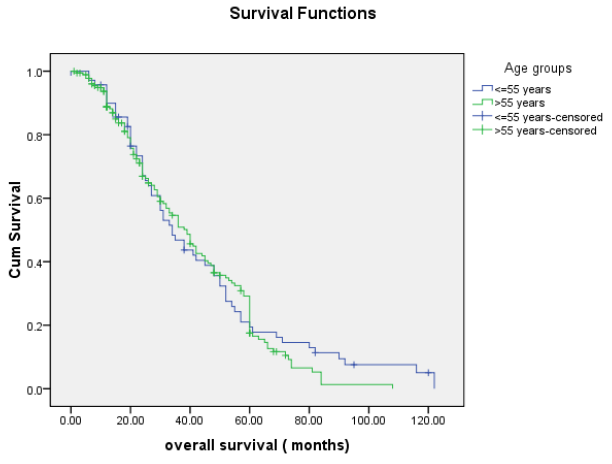

Figure 1: Kaplan-Meier curve of CLL patients (blue $=a g e<55$ years), (green=age $\geq 55$ years) 
As shown in figure 2; 35 older age CLL patients died due to other causes, while 14 older age CLL patients were died due to active disease and 4 younger age CLL patients died due to active disease, while 5 younger age CLL patients were died due to other causes although no significant difference $(p=0.3)$. (Figure 2)

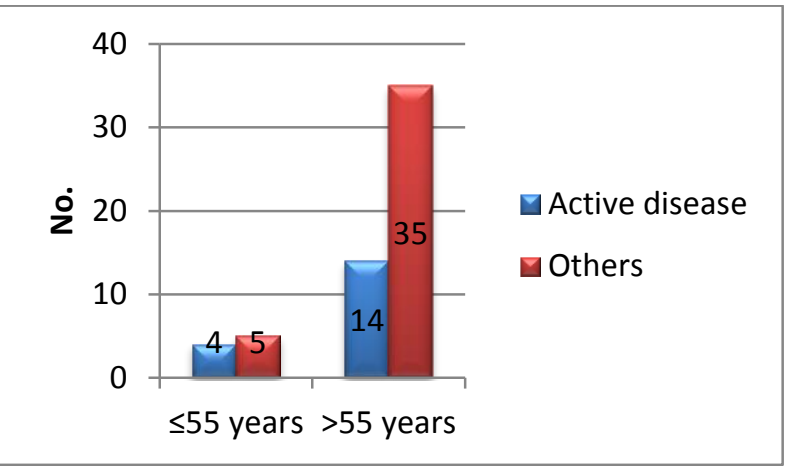

Figure 2: Distribution of death causes according to age group of CLL patients $(p=0.3)$.

\section{DISCUSSION}

Chronic lymphocytic leukemia is characterized by high heterogeneity. For that, assessing risk factors and prognostic indicators is essential in diagnosis and in planning for better treatment choices. These risk factors and prognostic markers are also helpful in prediction of survival and disease course in addition to predicting of treatment response ${ }^{26}$.

In present study, $72 \%$ of patients with chronic lymphocytic leukemia were at older age group ( $\geq 55$ years). This finding is close to results of Hasan study ${ }^{21}$ in Iraq which reported that median age of CLL patients in Kurdistan was (65 years) and $70.5 \%$ of them were at age of 60 years and more. Our study finding is also close to the results of the Alawadi et al ${ }^{27}$ study in Iraq which stated that $92.45 \%$ of studied CLL patients were in the age group between $50-70$ years with a mean age of 61.8 years. Present study found a significant association between weight loss presenting symptom of CLL and older age patients at diagnosis $(p=0.03)$. This finding is consistent with the results of Shephard et $a^{28}$ study in the UK which the results of Pamuk et al ${ }^{23}$ study in Turkey which reported no differences between younger age CLL patients and older age CLL patients regarding clinical presentation, laboratory investigations, clinical staging, and the treatment response. Inconsistently, Rai et al 10 reported a link between older age patients and advanced staging of CLL at diagnosis. In Spain, a study conducted by Baumann et al 30 on 949 patients with chronic lymphocytic leukemia found that elderly age patients presented with advanced CLL staging than younger age patients. Many authors revealed that earlier clinical features and signs associated with good prognosis were commonly found among younger age patients 24, 31, 32. The inconsistency between our study findings and other studies regarding physical signs and staging of CLL might be attributed to differences in prevalence and aggressiveness in CLL disease between our country and Western countries in addition to differences in study design and sampling size.
The current study found no significant differences between younger and older age CLL patients at diagnosis regarding treatment types. This finding is inconsistent with reports of Ferrajoli study in USA ${ }^{25}$ which stated that treatment should be started earlier among younger age patients with chemoimmunotherapy to improve their survival. This inconsistency might be due to lack of well organized national guideline for management of CLL patients and patients' non-compliance to physicians and recommended treatment regimens in our center. Our study results found a highly significant association between advanced ECOG performance scale and older age CLL patients at diagnosis $(p<0.001)$. Similarly, Liu et al 33 retrospective study in USA found that better functional status of patients was reported for younger age patients with hematological malignancies. In another American study, Shanafelt et al ${ }^{34}$ found that quality of life for patients with chronic lymphocytic leukemia was significantly lower among older age patients. In present study, there was a significant association between death outcome of CLL and older age patients at diagnosis $(p=0.01)$. This finding is consistent with the results of Al-Sawaf et al ${ }^{35}$ study in Germany which documented higher mortality rate among elderly age CLL patients in comparison to younger age CLL patients. However, our study findings regarding death outcome is inconsistent with results of Mauro et al ${ }^{30}$ study in Italy which reported that death rate related to CLL was significantly higher among younger age patients. This inconsistency might be due to differences in CLL disease demographic distribution between countries in addition to higher prevalence of elderly age population in Western countries as compared to our country. Although no significant difference, younger age CLL patients died from CLL active disease in present study were more prevalent than older age CLL patients. A previous Iraqi study found that a cause of death for patients with chronic lymphocytic leukemia was commonly related to active disease regardless of patients' age ${ }^{36}$. The current study showed that mean survival duration of younger age CLL patients at diagnosis was significantly longer than mean survival duration of older age CLL patients at diagnosis $(p=0.04)$. This finding is similar to results of many national and international works of literature such as Hasan study in the Kurdistan region-Iraq and Parikh et al study in the USA which all found that younger age CLL patients (age $\leq 55$ years) had significantly longer survival duration than older age CLL patients (age >55 years). On other hand, a multicenter analysis study carried in the USA out by Ujjani et al 37 reported no effect of age on treatment response and survival of CLL patients treated by lbrutinib, but revealed that elderly age patients died more and earlier than younger age patients. The difference might be due to concentrating on outcome of single treatment agent and not including other treatment types or untreated patients.

The current study concluded that clinical presentation, physical status, death rates and survival of patients with chronic lymphocytic leukemia in Kurdistan region-Iraq are different between young and older age patients. This study recommended the physician to take the age of patients with chronic lymphocytic leukemia in consideration throughout diagnosis, clinical staging, planning for treatment and prognosis. 
Acknowledgment: Great thanks to all medical health staff working in Tumor centers in Kurdistan for their efforts and help to complete my research.

Conflict of interest: Declared none.

\section{REFERENCES}

1. Kipps TJ, Stevenson FK, Wu CJ, Croce CM, Packham G, Weirda WG, et al. Chronic lymphocytic leukaemia. Nat Rev Dis Primers 2017; 3:16096.

2. Watson L, Wyld P, Catovsky D. Disease burden of chronic lymphocytic leukaemia within the European Union. Eur $\mathrm{J}$ Haematol 2008; 81:253-258.

3. Payandeh M, Sadeghi E, Sadeghi M. Survival and clinical aspects for patients with chronic lymphocytic leukemia in Kermanshah, Iran. Asian Pac J Cancer Prev 2015; 16:79877990.

4. Talibov M, Auvinen A, Weiderpass E, Hansen J, Martinsen JI, Kjaerheim K, et al. Occupational solvent exposure and adult chronic lymphocytic leukemia: No risk in a population-based case-control study in four Nordic countries. Int J Cancer 2017; 141(6):1140-1147.

5. Schubauer-Berigan MK, Daniels RD, Fleming DA, Markey AM, Couch JR, Ahrenholz SH, et al. Chronic lymphocytic leukaemia and radiation: findings among workers at five US nuclear facilities and a review of the recent literature. $\mathrm{Br} \mathrm{J}$ Haematol 2007; 139(5):799-808.

6. Kasim K, Levallois P, Abdous B, Auger P, Johnson KC; Canadian Cancer Registries Epidemiology Research Group. Environmental tobacco smoke and risk of adult leukemia. Epidemiology 2005; 16(5):672-680.

7. Dühren-von Minden $M$, Übelhart R, Schneider D, Wossning $T$, Bach MP, Buchner M, Hofmann D, Surova E, Follo M, Köhler F, Wardemann $\mathrm{H}$, Zirlik $\mathrm{K}$, Veelken $\mathrm{H}$, Jumaa $\mathrm{H}$. Chronic lymphocytic leukaemia is driven by antigen-independent cellautonomous signalling. Nature 2012; 489(7415):309-312.

8. Hallek M, Cheson BD, Catovsky D, Caligaris-Cappio F, Dighiero $\mathrm{G}$, Döhner $\mathrm{H}$, et al. iwCLL guidelines for diagnosis, indications for treatment, response assessment, and supportive management of CLL. Blood 2018; 131(25):2745-2760.

9. Reddy KS. Chronic lymphocytic leukaemia profiled for prognosis using a fluorescence in situ hybridisation panel. $\mathrm{Br} \mathrm{J}$ Haematol 2006; 132(6):705-722.

10. Rai KR, Sawitsky A, Cronkite EP, Chanana AD, Levy RN, Pasternack BS. Clinical staging of chronic lymphocytic leukemia. Blood 1975; 46(2):219-234.

11. Binet JL, Leporrier $M$, Dighiero $G$, Charron $D$, D'Athis $P$, Vaugier $G$, et al. A clinical staging system for chronic lymphocytic leukemia: prognostic significance. Cancer 1977; 40(2):855-864.

12. Hoechstetter MA, Busch R, Eichhorst B, Bühler A, Winkler D, Eckart MJ, et al. Early, risk-adapted treatment with fludarabine in Binet stage A chronic lymphocytic leukemia patients: results of the CLL1 trial of the German CLL study group. Leukemia 2017; 31(12):2833-2837.

13. Tausch E, Schneider C, Robrecht S, Zhang C, Dolnik A, Bloehdorn J, et al. Prognostic and predictive impact of genetic markers in patients with CLL treated with obinutuzumab and venetoclax. Blood 2020; 135(26):2402-2412.

14. Calin GA, Croce CM. Chronic lymphocytic leukemia: interplay between noncoding RNAs and protein-coding genes. Blood 2009; 114(23):4761-4770.

15. Hewamana S, Dearden C. Treatment options for high-risk chronic lymphocytic leukaemia. Ther Adv Hematol 2011; 2(3):147-159.

16. Oscier D, Fegan C, Hillmen $\mathrm{P}$, Illidge $T$, Johnson $\mathrm{S}$, Maguire $\mathrm{P}$, et al; Guidelines Working Group of the UK CLL Forum. British Committee for Standards in Haematology. Guidelines on the diagnosis and management of chronic lymphocytic leukaemia. $\mathrm{Br}$ J Haematol 2004; 125(3):294-317.

17. Gribben JG. How I treat CLL up front. Blood 2010; 115(2):187197.

18. Brenner $\mathrm{H}$, Gondos A, Pulte D. Trends in long-term survival of patients with chronic lymphocytic leukemia from the 1980s to the early 21 st century. Blood 2008; 111(10):4916-21.
19. Ivanescu AM, Oprea M, Momanu R, Coles E, Colita A, Lupu AR. Prognosis Factors in Chronic Lymphocytic Leukemia. J Med Life 2012; 5(Spec Issue):48-53.

20. Mjali A, Al-Shammari HHJ, Abbas NT, Azeez ZD, Abbas SK Leukemia Epidemiology in Karbala province of Iraq. Asian Pac $\mathrm{J}$ Cancer Care 2019; 4 (4): 135-139.

21. Hasan KM. Clinical Aspects, Immunophenotypic Analysis and Survival Rate of Chronic Lymphocytic Leukaemia Patients in Erbil City, Iraq. Sultan Qaboos Univ Med J 2018; 18(4):e461e467.

22. Al Tameemi WF. Efficacy of combination of rituximab therapy with chlorambucil plus prednisolone (R-LP) Protocol as treatment line in chronic lymphocytic leukemia patients. Iraqi J Hematology 2015; 4 (1): 1-15.

23. Pamuk GE, Pamuk ON, Soysal T, Ongören S, Başlar Z, Ferhanoğlu B, et al. An overview of young CLL patients: a singlecentre experience from Turkey. Haematologia (Budap) 2002; 31(4):303-311.

24. Mauro FR, Foa R, Giannarelli D, Cordone I, Crescenzi S, Pescarmona E, et al. Clinical characteristics and outcome of young chronic lymphocytic leukemia patients: a single institution study of 204 cases. Blood 1999; 94(2):448-454.

25. Ferrajoli A. Treatment of younger patients with chronic lymphocytic leukemia. Hematology Am Soc Hematol Educ Program 2010; 2010:82-89.

26. Yun $X$, Zhang $Y$, Wang $X$. Recent progress of prognostic biomarkers and risk scoring systems in chronic lymphocytic leukemia. Biomark Res 2020; 8: 40 . Available from: https://doi.org/10.1186/s40364-020-00222-3

27. Alawadi NB. Interleukin-6 Level among Iraqi Patients with Chronic Lymphocytic Leukemia from Babil Province. AlQadisiyah Medical Journal 2016; 12 (21): 112-123.

28. Shephard EA, Neal RD, Rose PW, Walter FM, Hamilton W. Symptoms of adult chronic and acute leukaemia before diagnosis: large primary care case-control studies using electronic records. Br J Gen Pract 2016; 66(644):e182-e188.

29. Bersabe AR, Romain JT, Ezzell EE, Renshaw JS. Chronic Lymphocytic Leukemia as an Unusual Cause of Rapid Airway Compromise. Case Rep Oncol Med 2017; 2017:8247353.

30. Baumann T, Delgado J, Santacruz R, Martínez-Trillos A, Royo C, Navarro A, et al. Chronic lymphocytic leukemia in the elderly: clinico-biological features, outcomes, and proposal of a prognostic model. Haematologica 2014; 99(10):1599-1604.

31. Molica S, Brugiatelli M, Callea V, Morabito F, Levato D, Nobile F, et al. Comparison of younger versus older B-cell chronic lymphocytic leukemia patients for clinical presentation and prognosis. A retrospective study of 53 cases. Eur J Haematol 1994; 52(4):216-221.

32. Delgado J, Villamor N. Chronic lymphocytic leukemia in young individuals revisited. Haematologica 2014; 99(1):4-5.

33. Liu MA, Hshieh T, Condron N, Wadleigh M, Abel GA, Driver JA. Relationship between physician and patient assessment of performance status and survival in a large cohort of patients with haematologic malignancies. Br J Cancer 2016; 115(7):858-861.

34. Shanafelt TD, Bowen D, Venkat C, Slager SL, Zent CS, Kay NE, et al. Quality of life in chronic lymphocytic leukemia: an international survey of 1482 patients. $\mathrm{Br} \mathrm{J}$ Haematol 2007; 139(2):255-264.

35. Al-Sawaf O, Bahlo J, Robrecht S, Fischer K, Herling CD, Hoechstetter M, et al. Outcome of patients aged 80 years or older treated for chronic lymphocytic leukaemia. $\mathrm{Br} \mathrm{J}$ Haematol 2018; 183(5):727-735

36. Naji A. Outcome of 49 Iraqi adult patients with Chronic Lymphocytic Leukemia treated with oral alkylating agent. J Fac Med Bagdad 2021; 54(2):126-30. Available from: https://iqjmc.uobaghdad.edu.iq/index.php/19JFacMedBaghdad3 6/article/view/

37. Ujjani C, Mato A, Hill BT, Allan JN, Lansigan F, Jacobs R, et al. The Impact of Age on Survival in CLL Patients Receiving Ibrutinib as Initial Therapy. Blood Lymphat Cancer 2020; 10:1-5. 